Miller Douglas (Orcid ID: 0000-0003-0707-0637)

Harris Gerald (Orcid ID: 0000-0002-7189-5839)

Diagnostic Ultrasound Safety Review for POCUS Practitioners

\title{
Diagnostic Ultrasound Safety Review for POCUS Practitioners
}

Douglas L. Miller PhD (corresponding author), University of Michigan Medical School, 3240A

Medical Science Bldg. 1, 1301 Catherine St., Ann Arbor, MI 48109-5667. Telephone: (734)

647-3344, Email: douglm@umich.edu.

Alyssa Abo MD, Dept. of Emergency Medicine, George Washington University School of

Medicine and Health Sciences, Washington DC

Jacques S. Abramowicz MD, Dept. of Obstetrics \& Gynecology, University of Chicago,

Chicago, IL.

Timothy A. Bigelow PhD, Center for Nondestructive Evaluation, Iowa State University, Ames,

IA

Diane Dalecki PhD, Department of Biomedical Engineering, University of Rochester, Rochester, NY

Eitan Dickman MD, Dept. of Emergency Medicine, Maimonides Medical Center, Brooklyn NY John Donlon, Acoustic Measurements, Philips Ultrasound, Bothell WA.

Gerald Harris PhD, Center for Devices and Radiological Health, US Food and Drug

Administration (retired), Silver Spring, MD

Jason Nomura MD, Dept. of Emergency Medicine, Christiana Hospital, Newark DE.

AIUM Bioeffects Committee, American Institute of Ultrasound in Medicine, 14750 Sweitzer

Lane, Suite 100, Laurel, MD

This is the author manuscript accepted for publication and has undergone full peer review but has not been through the copyediting, typesetting, pagination and proofreading process, which may lead to differences between this version and the Version of Record. Please cite this article as doi: $10.1002 /$ jum.15202

This article is protected by copyright. All rights reserved. 
Manuscript Category: Review Article

Running Title: Safety Review for POCUS

This article is protected by copyright. All rights reserved. 


\section{Summary}

Potential ultrasound-exposure safety issues are reviewed with guidance for prudent use of "point of care" ultrasound (POCUS). Safety assurance begins with the training of POCUS practitioners in the generation and interpretation of diagnostically valid and clinically relevant images. Sonographers themselves should minimize patient exposure in accordance with the aslow-as reasonably-achievable (ALARA) principle, particularly for the safety of eye, lung and fetus (SELF). ALARA-SELF entails the reduction of output indices or exposure duration, consistent with acquisition of diagnostically definitive images. Informed adoption of POCUS worldwide promises reduction of ionizing radiation risks, enhanced cost-effectiveness and prompt diagnoses for optimal patient care.

Key Words: Ultrasound Bioeffects, diagnostic ultrasound safety, point-of-care ultrasound, ALARA, Safety for Eye Lung and Fetus (SELF), Output Display Standard, Thermal Index, Mechanical Index, FDA Regulation.

This article is protected by copyright. All rights reserved. 


\section{Introduction}

Diagnostic ultrasound has provided non-ionizing radiation imaging for patient care for more than 50 years. In the past, the typical hospital diagnostic ultrasound machines were large cumbersome carts needing expert sonographers for production of useful diagnostic images, similar to CT or MRI procedures. However, advances in design of ultrasound machines have reduced the size while technological advances have improved image quality. In a radical departure from past practices, diagnostic ultrasound can now be easily portable and even 'handheld' - carried to the patient and applied by physicians or other trained individuals for immediate assessment and diagnosis with real time discussion leading to enhanced patient service. This advance compares to the introduction and adoption of the iconic physician's stethoscope in the $19^{\text {th }}$ century for auscultation, and provides physicians with versatile ultrasonic imaging of virtually any part of the body [1]. This development has created a new medical topic of “point-of-care ultrasound” (POCUS) [2]. The appearance of POCUS research publications in the medical literature (PubMed) is rapidly increasing, see Fig. 1, and testifies to its scientific validation and growing importance in medical practice.

The use of POCUS has revolutionized the ability of clinicians to diagnose patients at the bedside rapidly and accurately. There are virtually no specialties in the House of Medicine which do not employ ultrasonography, either for diagnostic purposes, procedural guidance, or both. Training programs in a variety of fields and specialties offer advanced training with this specific imaging modality, and increasingly, ultrasonography is incorporated into medical school

curricula. Ultrasonography offers a radiation-free, portable, and cost-effective means of imaging 
almost every part of the body.

\section{$\underline{\text { POCUS Patient Examinations }}$}

The rapidly expanding use of portable ultrasound machines allows diagnostic ultrasound to be performed by the physician at the bedside [3-5]. The total usage is impossible to determine because POCUS is performed in so many settings, often without billing records and often routinely on a daily basis to follow patient progress [6-8].

Rather than the comprehensive sonographic examination that typically is performed in the Radiology/ObGyn/Cardiology suite, POCUS provides a rapid answer to a specific clinical question. The versatility of ultrasound is extensive; see Table 1 for a list of clinical conditions that potentially can be ascertained with ultrasonography. For example, appropriately trained Emergency Physicians can effectively use ultrasound to accurately diagnose patients who present to the Emergency Department, including those with complaints related to early pregnancy [9], possible pericardial effusion [10], abdominal aortic aneurysm [11], undifferentiated shortness of breath [12], vision loss with retinal detachment [13] and those patients who have been traumatically injured [14]. The ability to perform and interpret these ultrasound examinations allows clinicians to diagnose potentially life-threatening conditions in a timely manner. In addition to the use of ultrasound in advanced healthcare environments, POCUS can be particularly beneficial in resource-poor locations. This modality can significantly alter management in places where other types of imaging are not available [15,16]. As an increasing number of physicians graduate from medical schools with knowledge of how to incorporate ultrasonography into their clinical practice, it is expected that the use of this technology will 
continue to grow in a wide variety of healthcare settings.

Similar to adult medicine, pediatrics exemplifies the broad scope of POCUS being used in several disciplines such as critical care, emergency medicine, anesthesia, surgical subspecialties, as well as outpatient and inpatient pediatrics. Furthermore, its use is being expanded to new environments such as urgent care. As the first imaging exam for many patients, POCUS is invaluable as it provides real-time data that can be integrated into medical decisionmaking. In addition, it has become an integral part of numerous procedures including central and peripheral vascular access, incision and drainage of soft tissue pathology, nerve blocks, lumbar punctures, and bladder catheterization, among others. Furthermore, POCUS can be used either once or in an ongoing manner to monitor patients, due to the lack of any accumulating dose-effect (in contrast to ionizing radiation).

Benefits of POCUS are appreciated and endorsed by various societies, including the World Federation of Ultrasound in Medicine and Biology [17], The American College of Emergency Medicine [18], the Society of Critical Care Medicine [19, 20] and the American Academy of Pediatrics [21], among others. However, the consideration of possible risk related to ultrasound exposure often is brief and lacking in rationale for safety guidance. Medical ultrasound originated as a means for tissue modification, and numerous applications of ultrasound for therapeutic purposes have been developed and are in extensive use [22]. Diagnostic ultrasound examinations must be configured carefully to avoid possible adverse consequences for the patient, through Food and Drug Administration (FDA) regulation and application of sonographer training. 
The non-ionizing radiation safety framework created by the FDA for assuring the safe use of diagnostic ultrasound with guideline upper limits on acoustic output has proven its worth as a flexible and effective system [23]. There have been no established occurrences of patient injury by diagnostic ultrasound [24, 25]. However, diagnostic ultrasound cannot be considered to be perfectly safe due to uncertainties about exposure dosimetry and potential injurious bioeffects. The safety issues are similar to those for all diagnostic ultrasound, but POCUS presents a new arena for assuring the safe use of diagnostic ultrasound. The purpose of this document is to briefly review and discuss potential ultrasound exposure safety issues and to outline guidance for prudent use of POCUS. As this was a review of existing literature and did not require the use of animals or patient data, ethical approval and request for obtaining informed consent were not required.

\section{Background of Diagnostic Ultrasound Safety Considerations}

Thermal and nonthermal physical mechanisms are operative during ultrasound exposure [26, 27]. There is essentially no risk of genetic injury from ultrasound (which exists for ionizing radiation in $\mathrm{X}$ rays, Positron Emission Tomography and Computed Tomography imaging). No universal dose quantity exists for ultrasound (such as the Gray, an ionizing radiation absorption quantity). The diagnostic ultrasound probe emits pulses of ultrasound which propagate into the body. There is no exposure to the operator, nor to bystanders, because ultrasound does not transmit into or propagate well in air, and the exposure is only to the tissues interacting with the pulses. The risks of specific biological effects induced by physical mechanisms of tissue 
perturbation can be characterized by a threshold exposure response to ultrasonic output and duration, with zero risk below a threshold but an increasing impact above the threshold [26]. Diagnostic ultrasound exposure and biological effect mechanisms

Figure 2 illustrates an ultrasound pulse and its acoustic parameters (measured in water). The waveform in Figure 2a displays the ultrasound pressure wave (for reference, atmospheric pressure is $0.1 \mathrm{MPa}$ ), which can be characterized by a peak rarefactional (negative) pressure amplitude and a mean frequency. The pulse carries momentum and has an intensity, calculated from the pulse waveform in units of $\mathrm{W} / \mathrm{cm}^{2}$ (Fig. 2b). Figure $2 \mathrm{c}$ and $2 \mathrm{~d}$ illustrate the exposure at a focal point during B-mode imaging, as the scanning beam of ultrasound passes by the measurement point, for an interval of a few pulse repetition periods, and for two full image frames. Note that the ultrasound exposure is minimal most of the time at a given point (e. g. the location of the small hydrophone used for pressure-field measurement) for scanned beams, so that the overall temporal-average intensity is much lower than the pulse-average intensity. Directed fixed beam modes (M mode and pulsed Doppler mode) have much higher temporalaverage intensities than imaging modes because the beam is not scanned. Ultrasonic energy is attenuated and absorbed in tissue depending upon the absorption coefficient of the tissue. The attenuation is moderate for tissues like liver, high for bone, and very high for lung, and typically increases in proportion to mean ultrasonic frequency. Absorption of ultrasound in tissue results in an exponential decrease in ultrasound intensity as a function of propagation distance, which limits the penetration of ultrasound into the body, and requires strong time-gain compensation to display images with depth uniformity. Even though the image appears uniform, the ultrasound 
exposure is much less for distal portions of an image relative to the focal point.

An assumption of safety for diagnostic ultrasound devices was codified by the Medical Device Amendments of 1976 enacted by the U.S. Congress. This act allowed for a simplified clearance process from the United States Food and Drug Administration (FDA) of new devices that were substantially equivalent in safety and effectiveness to devices legally marketed for the same applications before May 28, 1976. This law led to development of protocols for measurement of diagnostic ultrasound outputs, to the setting of guideline upper limits on the output of diagnostic ultrasound devices, and eventually to creation of exposure indices. Ultrasound machines are typically cleared for marketing by satisfying 510(k) premarket notification requirements of the FDA, including recommended upper limits to exposure parameters [23].

The FDA identified the acoustic intensity of ultrasound as the key quantity for regulation, and adopted the spatial-peak temporal-average intensity, ISPTA in $\mathrm{mW} \mathrm{cm}^{-2}$ and the spatial-peak pulse-average intensity, IsPPA in $\mathrm{W} \mathrm{cm}^{-2}$, for characterization. These quantities are calculated from measurements of the pulse pressure waveforms in water using a hydrophone (Fig. 2). Furthermore, these measured values are used to estimate the peak intensities in scanned tissue by adjusting for tissue attenuation of the ultrasound, a process called derating. An attenuation coefficient of $0.3 \mathrm{~dB} \mathrm{~cm}^{-1} \mathrm{MHz}^{-1}$ was adopted for this purpose as a conservative estimate of attenuation (typical tissues have higher coefficients) for safety. Using these methods and examination of pre-1976 devices, a table of maximal parameters was established for regulatory purposes. The values of IsPTA.3 and IsPPA.3 are listed in Table 2 (Mechanical Index values are also 
listed, see the section on “The real-time display of acoustic output”, below). Diagnostic ultrasound devices can be cleared by the FDA using these values via what is known as the Track 1 method of obtaining marketing clearance. An important feature of this Track 1 clearance method is that different recommended limits were established for different diagnostic ultrasound uses, with relatively low values for fetal (obstetrical) and ophthalmic uses.

\section{The real-time display of acoustic output}

Track 1 was unsatisfactory in that devices approved using this method have no indication of the actual acoustical output and exposure (except that it should be less that the Track 1 limits). In addition, the different values of ISPTA.3 and ISPPA.3 for different uses were not based on bioeffects studies, because such information was not available. Rather, to assist in FDA's decisions regarding substantial equivalence in terms of safety, they represented the maximum known output levels in each category for devices on the market before 1976 [28]. Physicians can prescribe use of an approved medical device for any examination deemed medically necessary, and the extent to which the Track 1 limits have been followed in practice is uncertain. The ultrasound community, specifically the American Institute of Ultrasound in Medicine and the National Equipment Manufacturers Association, worked with the FDA to create a standard for displaying output indicators to the sonographer that had defined relationships to physical mechanisms for biological effects of ultrasound [29]. This Output Display Standard was used to create a Track 3 method for device approval (there is no Track 2 method). This science-based method revolutionized the real-time assessment of exposure with direct relevance to safety and mostly eliminated the arbitrary limits for uses of modern diagnostic ultrasound machines (Table 
2), which can generally perform most of the different types of exams.

The absorption of ultrasonic energy in tissue leads to local tissue heating, thereby introducing a thermal mechanism with the potential for tissue injury. Thermal Indices (TI) were created to indicate the potential for heating during diagnostic ultrasound examinations. Heating is dependent on the tissue absorption coefficient, the temporal average intensity, and the duration of exposure at a particular point. As noted above, the relatively high IsPPA is reduced by pulsing the ultrasound to ISPTA, and heating is further reduced by scanning the ultrasound beam, and by the relative motion of the transducer and body. Heating is typically highest near the probe and at the beam focus. The values of the TI capture the relative risk of thermal damage mechanisms during the ultrasound exposure [30, 31]. Specifically, TI values translate the acoustic output of the ultrasound machine, quantified by the ISPTA, into an estimate of maximum potential temperature rise in ${ }^{\circ} \mathrm{C}$ in the tissue for long dwell times (i. e. the potential worst case). Since the ultrasound absorption properties vary based on tissue type, three different TI conditions have been defined. These are the TIS (Thermal Index Soft Tissue) for soft tissue applications, the TIB (Thermal Index Bone) when bone is expected to be present in the imaging region of interest where the ultrasound waves are focused, and the TIC (Thermal Index Cranium) when cranial bone is at the surface near the ultrasound probe. As a gauge of bioeffect risk, TI values less than or equal to 0.7 can be considered inconsequential for any duration, while values of 6 or higher indicate a risk of tissue injury for 1 min or longer durations, and are discouraged by regulatory guidance.

There are also nonthermal mechanisms for effects of ultrasound on tissues. Acoustic 
radiation force generated as ultrasonic energy is absorbed, or acoustic radiation pressure, generated when ultrasound reflects from a surface, can cause perturbation of tissue [32]. The physical perturbations can be biologically significant for high intensity focused ultrasound [33], but are small for diagnostic ultrasound with minimal expectation of harm. Radiation forces can lead to fluid flow, which can be evident in an ultrasound image and useful for distinguishing cysts from tumors [34]. Radiation forces can also cause local tissue displacement within the focal beam and are the basis for elastography imaging. For the diagnostic ultrasound mode of shear-wave elastography, radiation force impulses generate tissue displacement, which produces shear waves useful for mapping tissue elasticity [35].

Acoustic cavitation describes the interaction of an ultrasound field with existing gas bodies or microbubbles, and is another mechanism by which ultrasound can produce biological effects in tissue. Diagnostic ultrasound pressure amplitudes are sufficient (note that the peak negative pressure in Fig. 2a of about 2 MPa equals a negative stress of 20 times the magnitude of atmospheric pressure) to warrant consideration of the possible occurrence of ultrasonic inertial cavitation, which is associated with several biological effects. Inertial cavitation occurs when the ultrasound pulse interacts with a microscopic cavitation nucleus, such as a microbubble of gas. Above a peak rarefactional pressure amplitude threshold, the nucleus expands explosively to 2 or more times its initial diameter and then collapses under the inertia of the inrushing fluid. This phenomenon can kill nearby biological cells and damage blood vessels by mechanical processes, and furthermore cause damage by free radical generation due to temperatures exceeding 5,000 Kelvin at the collapse point. By calculating the inertial cavitation thresholds for 
many different microbubble sizes and ultrasound frequencies [36], minimum thresholds (for optimal nucleation) were found to increase as the square-root of frequency. This finding guided the creation of the on-screen Mechanical Index, defined as the peak rarefactional pressure amplitude (derated for tissue attenuation) divided by the square-root of the frequency and adjusted to in situ exposure. From the theory, the lowest threshold for inertial cavitation associated with the optimal size of nuclei (or microbubble) occurs at an MI $=0.4$. However, the guideline upper limit of output for diagnostic ultrasound devices was set at $\mathrm{MI}=1.9$. Of note, this limit value was determined from measurements of the output of a 2.25 MHz pre-1976 diagnostic ultrasound probe, and not by investigation of bioeffects and specific safety considerations [28]. The MI=1.9 value thus tolerates a theoretical risk of cavitational bioeffects possible under optimal conditions of nucleation for MIs in the range 0.4-1.9.

Current FDA 510(k) guidance for the Output Display Standard (Track 3) methods is given in Table 2. Manufacturers can choose to use either the IspPA.3 value or the MI value as the upper limit (note that these limits are different, and, for example, the IspPA.3 can exceed $190 \mathrm{~W}$ $\mathrm{cm}^{-2}$ at $\mathrm{MI}=1.9$ for ultrasonic frequencies greater than about $2.25 \mathrm{MHz}$ ). The two use categories are a global inclusion of most uses, and ophthalmic use. The difference in the two Tracks is noteworthy for obstetrical use: the ISPTA limit was effectively increased from 94 to $720 \mathrm{~mW} \mathrm{~cm}^{-2}$. The newer diagnostic ultrasound modes of elastography and contrast-agent enhanced diagnostic ultrasound were not noted specifically in the regulatory recommendations. However, elastography complies with the Track 3 methods: the radiation force impulses are relatively long, but have MI $<1.9$ and have IsPTA.3 $<720 \mathrm{~mW} \mathrm{~cm}^{-2}$ by virtue of relatively low pulse repetition 
frequencies (e. g. $1 \mathrm{~Hz}$ or less). The modes used for contrast-agent enhanced diagnostic ultrasound fall under the recommendations in Table 2, and it is the microbubble-based agents which receive separate FDA approval as injectable drugs (with recommended ultrasound parameter limits noted in the package inserts). All ultrasound machines that display the safety indices have an explanatory document "Medical Ultrasound Safety” [37] included in the operator's instructions or other documentation as required by FDA regulations. The vendors of diagnostic ultrasound equipment should help to supply safety information and to facilitate the prudent use of ultrasound exposure whenever possible.

\section{$\underline{A L A R A}$}

The dosimetry and thresholds for biological effects of diagnostic ultrasound are not definitively understood and therefore uncertainty exists as to the possible risks of harm. Research on patient risks has been limited, and in fact, it is impossible to prove the absence of risk. Risk may depend on individual patient physiology in addition to physical exposure parameters. To prudently accommodate these uncertainties, authoritative bodies assessing the diagnostic ultrasound safety problem have recommended the implementation of the As Low As Reasonably Achievable (ALARA) principle [26, 38, 39]. The operator is responsible for implementing ALARA during ultrasound examinations. That is, the exposure duration and the acoustical output should be kept as low as is reasonably achievable, consistent with collection of diagnostically acceptable images. The exposure indices were developed for display on diagnostic ultrasound machines to inform sonographers of exposure outputs related to thermal and mechanical (nonthermal) mechanisms, described above. As a benchmark low-risk condition, 
diagnostic output (excluding ophthalmology) with $\mathrm{MI}<0.4[40,41]$ and $\mathrm{TI}<0.7[42,43]$ are considered to be of negligible risk of ultrasound-induced biological effects for any exam duration. Simple instructions for implementing ALARA are [38]: “Select the right transducer, start with a low output level, and obtain the best image possible by using focusing, receiver gain, and other imaging controls. If that is not adequate for diagnostic purposes, then increase the output level. We can further implement ALARA by reducing the total ultrasonic exposure time.” Diagnostic ultrasound may be used without reservation in most examinations for medical indications or for appropriate POCUS practitioner training [44-46]. However, ALARA should include the elimination of diagnostic ultrasound exposure with no medical purpose or benefit.

\section{Safety Considerations for Specific POCUS Examinations}

The possible risk varies greatly for different imaging modes, examination regions in the

body, patient habitus and health status. A reasonable application of ALARA to diagnostic ultrasound should include adjustment of exposure Index values or duration for the exam at hand by knowledgeable sonographers. The following considerations of various types of POCUS examinations help to guide the safe use of diagnostic ultrasound. $\underline{\text { Imaging involving low absorption tissue without gaseous nuclei }}$

Many POCUS examinations are performed in adult tissues with low absorption giving TIS $<2$, and no bodies of gas [47], see Table 1. Liver and kidney are commonly examined for abnormal masses and blood flow. The heart is examined by echocardiography for assessment of function. Small parts imaging provides excellent images that can be presented at magnified image scales, and typically do not include bone or bodies of gas. Focused Assessment with 
Sonography in Trauma (FAST) examinations can detect blood in the abdomen and pericardium (for lung, see pulmonary POCUS below). Diagnostic interventional ultrasound for guided vascular access or fine needle aspiration are excellent for reduction of potential patient injury through control of the penetrating needle. Tissues in the body wall, including intercostal spaces and abdominal wall, likewise have no bone or gas bodies in the imaging path.

Critically, the body does not appear to contain optimum cavitation nuclei for diagnostic ultrasound, likely due to the complete wetting and sterilization processes active in living tissue. Research on the occurrence of inertial cavitation in response to diagnostic ultrasound imaging of normal tissue has been negative, indicating that inertial cavitation-induced injury is non-existent or very rare for diagnostic ultrasound without the presence of microbubble contrast agents. Therefore, the Mechanical Index should be considered to be a general nonthermal exposure index, rather than a specific cavitation index (except for contrast enhanced diagnostic ultrasound, discussed below).

These examinations also typically use imaging with low TI values (low temporal-average intensity) even at the maximum output. Heating is least for the low absorption soft tissues (i. e. other than bone or cranium) and presents minimal risk of injury, particularly in adults, for TI $<2$ even for lengthy exposure times, as listed in Table 3. Therefore, the risk of injury from the thermal mechanism is also very low.

For low absorption tissue without gaseous nuclei, the maximum output can be used with very low risk of patient injury from the ultrasound exposure. The ALARA principle should still be applied when reduced output imaging produces diagnostically optimal images in order to 
avoid higher exposures with no additional medical value.

\section{Contrast Enhanced POCUS}

The use of ultrasound contrast agents to improve suboptimal ultrasound images and provide additional diagnostic information can be useful in several different situations such as echocardiography and assessment of liver masses [48, 49]. Contrast enhanced diagnostic ultrasound requires venous access for contrast agent injection along with coordinated timing of injection and imaging. Contrast agents are suspensions of stabilized microbubbles, which are designed for long circulation times and strong echo response.

Contrast enhanced diagnostic ultrasound has a known potential risk factor due to cavitation nucleation from the stabilized microbubbles [50]. This risk can be mitigated by use of low MI imaging modes ( $\mathrm{MI}<0.4)$ designed for microbubble persistence and optimal contrast enhancement. However, there are also non-ultrasound related risks, although rare, such as injection site complications, Complement Activation Related Pseudo-Allergy (CARPA), and other anaphylactoid and allergic reactions [40, 49].

Use of contrast enhanced ultrasound is beginning to expand into the point of care setting focusing on cardiac and trauma related indications [51, 52]. However, given the complex interaction of contrast agent, examination protocol and system settings that can alter the cavitation risk, detailed safety parameters are beyond the setting of this review. In general, for imaging with contrast agents at an MI above 0.4, practitioners should use the minimal agent dose, MI, and examination time consistent with efficacious acquisition of diagnostic information. Head, musculoskeletal examinations with bone and high TI modes 
Musculoskeletal POCUS can be valuable for numerous diagnoses of head and musculoskeletal examinations (Table 1). A classic example of an important diagnosis perfectly suited to POCUS is examination for rib fractures. Griffith et al [53] found that rib sonography was better at detecting rib fractures than chest radiography. Additional uses include assessment for skull fracture, neonatal interventricular hemorrhage, transcranial Doppler, fluid in sinuses, etc.

These examinations are not expected to involve cavitation risk. However, bone and tendon have high absorption coefficients and will heat faster and to higher temperatures than soft tissue. The TI for bone (TIB) should be used for guidance when examinations involve bone and the TI for the cranium (TIC) should be used for examination of the head. For high TI (>0.7) conditions, the exposure time should be limited during an examination. A multi-step system is shown in Fig. 3 and Table 3 [43, 54]. In febrile patients, the temperature elevation should be added to the on-screen TI to determine the exposure time. The exposure time limit decreases exponentially with increasing TI (the horizontal scale in Fig. 3 is logarithmic). Sonographers encountering the higher TI values may advantageously reduce the TI (power output) to avoid hurried performance of difficult exams. For a TI of 5, a 50\% reduction in power $(-3 \mathrm{~dB}$, equivalent to an MI reduction, for example, from 1.4 to 1.0) cuts the TI in half, thereby allowing an exposure time of $1 \mathrm{~h}$ rather than $1 \mathrm{~min}$.

\section{Ophthalmic POCUS}

Ocular ultrasound is used at the bedside to diagnose many ophthalmic conditions, including intraocular or periorbital foreign bodies, globe rupture, hyphema, lens dislocation, lens 
subluxation, retinal detachment, retinal hemorrhage, vitreous detachment, vitreous hemorrhage, choroidal detachment, papilledema, increased intracranial pressure, neoplasms, and vascular pathologies [55, 56]. The examination typically is conducted with a 7-15 MHz, small-footprint linear probe coupled to the closed eyelid with a copious amount of gel to permit successful visualization without excessive pressure to the globe. If the ultrasound device lacks an “ophthalmic" preset, then frequently a "small parts” preset is chosen. B-mode imaging is used for identifying anatomical abnormalities and the presence and location of foreign bodies, while Doppler ultrasound, both color and spectral, finds use in examining blood flow in the ophthalmic and central retinal arteries and veins [55].

The possibility of both thermal and nonthermal bioeffects should be considered in the eye. In a review by van Rhoon et al. [57], safe thresholds for temperature rise in various tissues and organs, including the eye, were expressed in terms of thermal dose of cumulative effective minutes at $43^{\circ} \mathrm{C}$ (CEM43). The most sensitive eye structures were the lens, cornea, and retina, with the lowest CEM43 value being 2.4 minutes for the lens. One could base temperatureexposure time thresholds on this value, or alternatively, take a more conservative thermal dosebased approach by using the AIUM [41] "Statement on Mammalian Biological Effects of Ultrasound In Vivo” for fetal exposures to set a CEM43 of 0.125 minutes for the eye. The eye and early first-trimester embryo have some comparable characteristics in that they can have similar size, neither is well-perfused, and protein is present [58]. However, a practical problem with either of these thermal dose approaches is that users only have access to the TI, not the actual temperature rise, and studies have found that the TIS could greatly underestimate the 
actual temperature rise in the eye [59,60]. The likely reason is that the generic tissue models used for the TIS are not appropriate for the eye, chiefly due to the relatively large absorption in the lens and orbital fat; also, the eye is poorly perfused. To offer some guidance, the British Medical Ultrasound Society has recommended not to exceed a TI of 1 when scanning the eye [61].

Regarding nonthermal bioeffects, the eye normally has no gas body content. However, there are some clinical situations such as trauma, surgery, or after the use of perfluorocarbon gases for treatment of retinal detachment in which gas bodies might be present [62]. In these cases, the risk of cavitational nonthermal effects is possible.

Development of TI and MI recommendations for eye exams is challenging because the aforementioned generic tissue models used for calculating these indices are not applicable for the eye. For this reason, the FDA diagnostic ultrasound guidance [23] has lower recommended maximum exposure levels for ophthalmic exams of IsPTA. $3 \leq 50 \mathrm{~mW} \mathrm{~cm}^{-2}, \mathrm{MI} \leq 0.23$, and $\mathrm{TI} \leq 1$ for devices that follow the Output Display Standard (Table 2). Temperature rise measurements in the eye due to ultrasound exposure have been described in several papers, which indicate that the risk of thermal injury is mitigated by the FDA guidelines for ophthalmic exams [60, 62, 63]. Silverman et al. [62] studied the safety of very high frequency diagnostic ultrasound (ultrasonic biomicroscopy) at $38 \mathrm{MHz}$ and found no injury in histology for up to 30 min exposure of rabbit cornea or lens with IsPTA.3 $=34 \mathrm{~mW} / \mathrm{cm}^{2}$ (i. e. less than the FDA recommended limit of 50 $\mathrm{mW} / \mathrm{cm}^{2}$ ). In general, the eye should only be evaluated if there is an ophthalmologic preset on the system. If ophthalmologic setting is not available, the patient should be informed that the scan is an off-label use and give appropriate informed consent. 


\section{$\underline{\text { Pulmonary POCUS }}$}

The first accepted use of pulmonary diagnostic ultrasound was to rule out pneumothorax [64]. Subsequently, diagnostic ultrasound has been found to be valuable in the diagnosis of pneumonia, pulmonary edema, pulmonary embolism, atelectasis, diffuse parenchymal disease, respiratory distress syndrome, and lung cancer [65]. The pleura appears in the image as a hyperechoic line. Artifacts are used to facilitate a variety of diagnoses, including B lines (comettail artifacts), which are diagnostic for pulmonary edema or interstitial lung disease [66]. Chest sonography is used in children for the diagnosis of neonatal respiratory distress syndrome [67], pneumonia [68-70], and other neonatal pulmonary diseases using POCUS [71]. The assessments of B-lines and other image features are valuable in neonatal examinations for diagnosis of respiratory distress syndrome [72], assessing surfactant treatment [73], pulmonary hemorrhage [74] and the number of B lines correlates with computed tomography findings [75]. The total usage of pulmonary diagnostic ultrasound is impossible to determine because POCUS is performed in so many settings, and often routinely on a daily basis to follow patient progress.

The biological effect of pulmonary capillary hemorrhage (PCH) produced by pulsed ultrasound exposure relevant to diagnostic imaging was discovered more than $25 \mathrm{y}$ ago in mice, [76] and has been confirmed in mice, rats, rabbits, pigs and monkeys. Direct human bioeffects research ethically cannot be done, although an early clinical study (B lines were not yet established as a lung ultrasound finding) was conducted to check for PCH on lungs of adult humans undergoing transesophageal echocardiography with exposure of the lung and thoracotomy, allowing lung examination [85]. No hemorrhage was noted by the surgeon on 
gross examination of the lungs. Recent results on the induction of pulmonary capillary hemorrhage from diagnostic ultrasound imaging in rats was comparable to early results with laboratory pulsed ultrasound, and the ultrasound images displayed B lines associated with the occurrence and progression of this bioeffect $[77,78]$. Animal research has shown that the PCH bioeffect depends on physical parameters, such as the ultrasound mode [79] and duration [80], in addition to the MI. Biological factors also are very important, including sedation [81], ventilation [82], age and lung position [83] and animal species [84].

The physical mechanism for the PCH bioeffect is uncertain, because both the thermal mechanism and cavitation have been ruled out, and a nonthermal mechanism such as acoustical radiation force or pressure may be important [86]. The most recent consensus report of the American Institute of Ultrasound in Medicine [87] states that, although it was clear that pulmonary capillary hemorrhage might occur during realistic diagnostic exposures above an MI of 0.4 , patient risk should be minimal for diagnostic ultrasound, because only incidental lung exposure was expected. However, as noted above, pulmonary diagnostic ultrasound is now routine and widely performed using portable point-of-care machines. Clear application of the ALARA principle is needed.

Unfortunately, the B line sign of pulmonary capillary hemorrhage induction is not useful for safety guidance. The possibility of PCH induction for pulmonary examinations for MI $>0.4$ likely can be excluded when no B lines are seen, although very small PCH can escape detection [80]. However, the possibility of ultrasonic PCH induction for pulmonary examinations with MI $>0.4$ cannot be excluded when B lines are seen, due to ambiguity in the origin and persistence 
of the B lines. B line artifacts being sought for diagnostic indications and those being induced by the diagnostic ultrasound itself would be impossible to clearly distinguish, particularly in clinical exams, due to large variation in B line appearance with lung sliding and hand motion of the probe.

The prudent safety guidance for pulmonary ultrasound is to practice ALARA with an $\mathrm{MI}<0.4$ in many patients. Because the lung surface is often at shallow depth, $0.7 \mathrm{~cm}$ even in some adults [88], pulmonary images may be obtained at a reduced MI. An additional safety margin exists for many pulmonary exams, such as in high BMI patients, because the intercostal tissue has a relatively high absorption coefficient of about $1.2 \mathrm{~dB} \mathrm{~cm}^{-1} \mathrm{MHz}^{-1}$ (which is higher than the value (0.3) assumed for the MI). The actual exposure at the pleura will be less than that indicated by the on-screen MI. For a chest wall thickness of $4 \mathrm{~cm}$ and an ultrasound frequency of $6 \mathrm{MHz}$, not an uncommon configuration, the exposure implied by the on-screen MI could be less by a factor of 10 at the visceral pleura, mitigating the risk of lung injury for MI>0.4. These considerations should be factored in to the patient-specific application of the ALARA principle, consistent with acquisition of diagnostically acceptable images.

\section{$\underline{\text { Obstetrical POCUS }}$}

Ultrasound is the imaging modality of choice for obstetrics- and gynecology-related emergencies as it can be used to rapidly identify the uterus and its contents. In addition, the adnexa can be evaluated and the pelvis can be assessed for the presence of free fluid. Transabdominal ultrasound (TAU) scanning will be the first approach but trans-vaginal ultrasound (TVU) will often be needed for its superior resolution. Common causes of acute lower 
abdominal pain in females include ovulation pain, ovarian torsion, hemorrhagic cysts, endometriosis, pelvic inflammatory disease, ectopic pregnancy, issues with an intra-uterine contraceptive device, degenerating fibroids, as well as non-gynecologic causes such as appendicitis. In obstetrics, POCUS can be used as a straightforward and accurate method to visualize an intra-uterine pregnancy from 5-6 weeks gestation to term. One of the most common indications for POCUS is abdominal pain in a patient with a positive pregnancy test. Besides location of the pregnancy, ultrasound can be used to confirm viability (presence of a fetal heartbeat), fetal number, gestational age and, later in pregnancy, to assess fetal presentation, growth and wellbeing as well as placental location, cervical length and quantity of amniotic fluid [89]. Ultrasound is also used for prenatal imaging of fetal ocular and orbital abnormalities [90]. While there are no concerns with the use of ultrasound in gynecology, whenever there is the possibility of an intrauterine pregnancy, caution should be exercised [58]. The developing fetus is mostly susceptible to external insults in the first 10-12 weeks of pregnancy, the time of embryogenesis/organogenesis. The use of prenatal ultrasound for inspection of the eyes also introduces the safety considerations for the eye, noted above in the Ophthalmic POCUS section. Importantly, a 20 year follow up study of a randomized controlled trial found that no significant impact on visual outcomes or ocular biometry was associated with frequent in-utero ultrasound (B mode and spectral Doppler mode, likely including ocular exposure) [91]. The occurrence of cavitational bioeffects or pulmonary capillary injury in the fetus is unlikely due to an absence of cavitation nuclei and the lack of gas in the fetal lungs and bowels. However, heat is a known teratological agent, from animal research as well as from the described incidence of fetal 
anomalies in human mothers with elevated temperature from infection early in pregnancy or secondary to an excessive use of hot baths or saunas. Therefore precaution is necessary, particularly in modes that can generate higher acoustic outputs, such as spectral (pulsed) Doppler mode. This has led to joint statement recommending against the routine use of pulsed Doppler in the first trimester [39]. In keeping with the ALARA principle this would advocate for using M mode and not using pulsed Doppler for the measurement of fetal heart rate alone.

The general recommendation should be to keep the examination as short as possible, with as low as possible acoustic outputs but sufficient to arrive at the correct diagnosis (ALARA principle). The thermal index TIS should be used prior to 10 weeks and the TIB after 10 weeks. Detailed advice on the maximum scanning time for a given TI is listed in Table 3. As for the adult case, a reduction in output can greatly lengthen the recommended scanning time limit. For example, a reduction in output power of $50 \%$ for a TI of $\sim 3$ reduces the TI to $\sim 1.5$, thereby allowing an exposure time of up to 30 min rather than $<1$ min.

\section{Discussion of Ultrasound Safety in the POCUS Perspective}

\section{$\underline{\text { Reduction in Ionizing Radiation Dose }}$}

This review has focused on safety considerations for non-ionizing ultrasound exposure. However, it should be noted that POCUS has no risk of bioeffects such as cancer, and no trend for increasing risk with exposure accumulation, as are well known for ionizing radiation doses. This feature of ultrasound examination provides an overall benefit by reducing ionizing radiation

dose. POCUS is growing throughout all medical specialties, including Pediatrics. Historically, 
ultrasound in pediatrics was used in traditional ways by both Radiology and Cardiology. The goal of bedside ultrasound, aka POCUS, is to provide real-time information to clinicians at the point-of-care to guide medical decision-making and provide procedural guidance. It is well established that radiation exposure in children has long-term effects [92-96]. Use of ultrasound can reduce the ionizing radiation exposure substantially. For example, POCUS has proven of value for monitoring Crohn's disease in children [97] and can greatly reduce the cumulative ionizing radiation dose over the long course of this disease [98].

\section{Hands on training for high quality POCUS}

The most important factor for POCUS efficacy and safety is operator training. Physicians and other medical personnel who may use POCUS must understand the principles of ultrasound imaging, the use of the exposure indices, and how to produce images of diagnostic value. Missed or incorrect diagnoses can have substantial adverse consequences for the patient. Numerous training guides are available, for example, in surgery residency [99], anesthesiology [100], pediatrics [101], emergency medicine [18], resource limited emergency physicians [102], critical care [19] and clinical practice [103]. Hands-on training is critical, and represents an important medical application of diagnostic ultrasound (with attention for potential incidental findings of medical importance) $[45,46]$. Ultrasound imaging has become more and more clear and accurate, but will show nothing of value in the wrong hands. A particularly exciting aspect of POCUS is that appropriate training including safety and image interpretation potentially can be given to many non-physician medical personnel and bring the benefits of POCUS to virtually any patient in need; for example, in remote rural areas [104, 105]. 


\section{Summary of POCUS Safety Guidance}

Diagnostic ultrasound exposure is regulated for safety and may be used without reservation in most examinations for medical indications or for appropriate POCUS practitioner training. Non-medical uses should be minimized or avoided [44]. No diagnostic-ultrasound induced adverse biological effects have been demonstrated and confirmed in humans, but very little definitive human experimentation has been performed (due to problematical ethics and low sensitivity). Based on theoretical considerations and definitive animal studies, special attention and prudent use of the ALARA principle should be considered in three situations. The eye is particularly vulnerable and has special, separate FDA guidelines (Table 2), which must be set by the user for most ultrasound machines. The surface of the lung is excellent for diagnostic examination but may have a risk of capillary hemorrhage in some patients who are thin or treated by some medications. The fetus, as always, must prudently be considered to be vulnerable and examined with care by using the correct TI value for exposure limitation. Sonographers themselves must practice ALARA patient exposure during POCUS. Remembering these special situations may be aided by the acronym: Safety for Eye Lung and Fetus (SELF).

POCUS represents a revolution in patient care with timely and high value diagnostic information. It is cost effective and can fill the need for medical imaging in many venues including the most remote settings. With few areas of concern for ultrasound exposure, the use of POCUS can reduce patient exposure to ionizing radiation, which is an overall benefit for patient safety. Continued growth and acceptance of POCUS will provide optimum patient care. 
This article is protected by copyright. All rights reserved. 


\section{References}

1. Solomon SD, Saldana F. Point-of-care ultrasound in medical education--stop listening and look. N Engl J Med. 2014;370:1083-5.

2. Moore CL, Copel JA. Point-of-care ultrasonography. N Engl J Med. 2011;364:749-57.

3. Lumb P, Karakitsos D eds. Section VI General Chest Ultrasound. Critical Care Ultrasound. (Philadelphia: Elsevier, 2015) pp 105-137.

4. Irwin Z, Cook JO. Advances in Point-of-Care Thoracic Ultrasound. Emerg Med Clin North Am. 2016;34:151-157.

5. Sekiguchi H. Tools of the Trade: Point-of-Care Ultrasonography as a Stethoscope. Semin Respir Crit Care Med. 2016;37:68-87.

6. Hall MK, Hall J, Gross CP, et. al. Use of point-of-care ultrasound in the emergency department: insights from the 2012 Medicare National Payment Data Set. J Ultrasound Med. 2016;35:2467-2474.

7. Sferrazza Papa GF, Mondoni M, Volpicelli G, et al. Point-of-Care Lung Sonography: An Audit of 1150 Examinations. J Ultrasound Med. 2017;36:1687-1692.

8. Buerger AM, Clark KR. Point-of-Care Ultrasound: A Trend in Health Care. Radiol Technol. 2017;89:127-138.

9. Panebianco NL, Shofer F, Fields JM, et al. The Utility of Transvaginal Ultrasound in the ED evaluation of complications of first trimester pregnancy. Am J Emerg Med. 2015; 33: 743-8.

10. Mandavia D.P., Hoffner R.J., Mahaney K. Bedside echocardiography by emergency physicians. Ann Emerg Med. 2001;38:377-382.

This article is protected by copyright. All rights reserved. 
11. Kuhn M., Bonnin R.L., Davey M.J. Emergency department ultrasound scanning for abdominal aortic aneurysm: accessible, accurate, and advantageous. Ann Emerg Med. 2000;36:219-223.

12. Guttikonda SNR, Vadapalli K. Approach to undifferentiated dyspnea in emergency department: Aids in rapid clinical decision-making. Int J Emerg Med. 2018;11: 21.

13. Gottlieb M, Hollday D, Peksa GD. Diagosis of Retinal Detachment: A Systemic Review and Meta-Analysis. Acad Emerg Med 2019:00:1-9.

14. Melniker L.A., Leibner E., McKenney M.G. Randomized controlled clinical trial of point-ofcare, limited ultrasonography for trauma in the emergency department; the first sonography outcomes assessment program trial. Ann Emerg Med. 2006;235:227-235

15. Stachura M, Landes M, Aklilu F, et al. Evaluation of a point of care ultrasound scan list in a resource-limited emergency centre in Addis Ababa Ethiopia. Afr J Emerg Med. 2017;7:118123.

16. Shah SP, Shah SP, Fils-Aime R, Desir W, Joasil J, Venesy DM, Muruganandan KM. Focused cardiopulmonary ultrasound for assessment of dyspnea in a resource-limited setting. Crit Ultrasound J. 2016;8:7.

17. Dietrich CF, Goudie A, Chiorean L, et al. Point of Care Ultrasound: A WFUMB Position Paper. Ultrasound Med Biol. 2017;43:49-58.

18. American College of Emergency Physicians. Ultrasound Guidelines: Emergency, Point of Care, and Clinical Ultrasound Guidelines in Medicine. Ann Emerg Med 2017;69:e27-54. 19. Frankel HL, Kirkpatrick AW, Elbarbary M, et al. Guidelines for the Appropriate Use of 
Bedside General and Cardiac Ultrasonography in the Evaluation of Critically Ill PatientsPart I: General Ultrasonography. Crit Care Med. 2015;43:2479-502.

20. Levitov A, Frankel HL, Blaivas M, Kirkpatrick AW, Su E, Evans D, Summerfield DT, Slonim A, Breitkreutz R, Price S, McLaughlin M, Marik PE, Elbarbary M. Guidelines for the Appropriate Use of Bedside General and Cardiac Ultrasonography in the Evaluation of Critically Ill Patients-Part II: Cardiac Ultrasonography. Crit Care Med. 2016;44:1206-27.

21. Marin JR, Abo AM, Arroyo AC, et al. Pediatric emergency medicine point-of-care ultrasound: summary of the evidence. Crit Ultrasound J. 2016;8:16.

22. Miller DL, Smith NB, Bailey MR, Czarnota GJ, Hynynen K, Makin IR; Bioeffects Committee of the American Institute of Ultrasound in Medicine. Overview of therapeutic ultrasound applications and safety considerations. J Ultrasound Med. 2012;31:623-34.

23. FDA Guidance for Industry and FDA Staff - Information for Manufacturers Seeking Marketing Clearance of Diagnostic Ultrasound Systems and Transducers,” September 9, 2008.

24. American Institute of Ultrasound in Medicine, Statement on Prudent use and clinical safety. AIUM Official Statements, www.aium.org, 2012.

25. WFUMB. WFUMB clinical safety statement for diagnostic ultrasound-an overview. World Federation for Ultasound in Medicne and Biology. 2018, www.wfumb.org/safetystatements.

26. Nyborg WL, Carson PL, Carstensen EL, et al. Exposure Criteria for Medical Diagnostic Ultrasound: II. Criteria Based on All Known Mechanisms. (Report No. 140, National 
Council on Radiation Protection and Measurements, Bethesda Md.; 2002).

27. O'Brien, W. D. Jr, Deng, C. X., Harris, G. R., et al. (2008) The risk of exposure to diagnostic ultrasound in postnatal subjects: thermal effects. J Ultrasound Med. 27, 517-535.

28. Nyborg, W. L: (2000). Biological effects of ultrasound: development of safety guidelines.

Part I: personal histories. Ultrasound Med Biol. 26, 911-64.

29. AIUM/NEMA, Standard for Real-Time Display of Thermal and Mechanical Acoustic Output Indices on Diagnostic Ultrasound Equipment, Revision 2. NEMA Standards Publication UD 3-2004; American Institute of Ultrasound in Medicine, Laurel MD; National Electrical Manufacturers Association, Rosslyn, VA; 2004

30. Abbott JG. Rationale and derivation of MI and TI--a review. Ultrasound Med Biol. 1999;25:431-41.

31. Bigelow TA, Church CC, Sandstrom K, et al. The thermal index: its strengths, weaknesses, and proposed improvements. J Ultrasound Med. 2011;30:714-34.

32. Starritt HC. Radiation force and its possible biological effects. In G. Ter Haar ed. The Safe Use of Ultrasound in Medical Diagnosis, $3^{\text {rd }}$ edition, (British Institute of Radiology, London, 2012) Chapt. 7.

33. Simon JC, Sapozhnikov OA, Wang YN, Khokhlova VA, Crum LA, Bailey MR. Investigation into the mechanisms of tissue atomization by high-intensity focused ultrasound. Ultrasound Med Biol. 2015;41:1372-85.

34. Chatterton BE, Spyropoulos P. Colour Doppler induced streaming: an indicator of the liquid nature of lesions. Br J Radiol. 1998;71:1310-2. 
35. Sigrist RMS, Liau J, Kaffas AE, Chammas MC, Willmann JK. Ultrasound elastography: review of techniques and clinical applications. Theranostics. 2017;7:1303-1329.

36. Apfel, R. E., and Holland, C. K. (1991) Gauging the likelihood of cavitation from shortpulse, low-duty cycle diagnostic ultrasound. Ultrasound Med Biol. 17, 179-185.

37. American Institute of Ultrasound in Medicine, Medical Ultrasound Safety, 3rd Ed., AIUM, www.aium.org, 2014.

38. American Institute of Ultrasound in Medicine, As Low As Reasonably Achievable (ALARA) Principle. AIUM Official Statements, www.aium.org, 2014.

39. WFUMB. WFUMB policy and statements on safety of ultrasound. Ultrasound Med Biol. 2013;39:926-9.

40. American Institute of Ultrasound in Medicine, Statement on Mammalian Biological Effects in Tissues with Gas Body Contrast Agents. AIUM Official Statements, www.aium.org, 2015a.

40. Muskula PR, Main ML. Safety With Echocardiographic Contrast Agents. Circ Cardiovasc Imaging. 2017;10(4).

41. American Institute of Ultrasound in Medicine, Statement on Mammalian Biological Effects of Ultrasound in Vivo. AIUM Official Statements, www.aium.org, 2015b.

42. American Institute of Ultrasound in Medicine, Statement on the Safe Use of Doppler Ultrasound During 11-14 week scans (or earlier in pregnancy). AIUM Official Statements, www.aium.org, 2016a.

43. American Institute of Ultrasound in Medicine, Recommended Maximum Scanning Times for 
Displayed Thermal Index (TI) Values. AIUM Official Statements, www.aium.org, 2016b.

44. Barnett SB, Abramowicz JS, Ziskin MC, Marsál K, Claudon M. WFUMB Symposium on Safety of Nonmedical Use of Ultrasound. Ultrasound Med Biol. 2010;36:1209-12.

45. American Institute of Ultrasound in Medicine, Safety in diagnostic Ultrasound Educational Activities using Non-Pregnant Subjects. AIUM Official Statements, www.aium.org, 2019.

46. American Institute of Ultrasound in Medicine, Safety in diagnostic Ultrasound Educational Activities using Pregnant Subjects. AIUM Official Statements, www.aium.org, 2019.

47. Nobel VE, Nelson BP. Manual of Emergency and Critical Care Ultrasound $2{ }^{\text {nd }}$ Ed. (Cambridge, Cambridge University Press, 2011).

48. Piscaglia F, Nolsøe C, Dietrich CF, et al. The EFSUMB Guidelines and Recommendations on the Clinical Practice of Contrast Enhanced Ultrasound (CEUS): update 2011 on nonhepatic applications. Ultraschall Med. 2012;33:33-59.

49. Claudon M, Dietrich CF, Choi BI, et al. Guidelines and good clinical practice recommendations for Contrast Enhanced Ultrasound (CEUS) in the liver - update 2012: A WFUMB-EFSUMB initiative in cooperation with representatives of AFSUMB, AIUM, ASUM, FLAUS and ICUS. Ultrasound Med Biol. 2013;39:187-210.

50. Miller DL, Averkiou MA, Brayman AA, et al. Bioeffects considerations for diagnostic ultrasound contrast agents. J Ultrasound Med. 2008;27:611-36.

51. Kummer T, Oh L, Phelan MB, Huang RD, Nomura JT, Adhikari S. Emergency and Critical Care Applications for Contrast Enhanced Ultrasound. Am J Emerg Med. 2018;35:12871294.

This article is protected by copyright. All rights reserved. 
52. Lv F, Ning Y, Zhou X, et al. Effectiveness of Contrast Enhanced Ultrasound in the Classification and Emergency Management of Abdominal Trauma. Eur Radiol. 2014;24:2640-2648.

53. Griffith JF, Rainer TH, Ching AS, Law KL, Cocks RA, Metreweli C. Sonography compared with radiography in revealing acute rib fracture. AJR Am J Roentgenol. 1999;173:1603-9.

54. Harris GR, Church CC, Dalecki D, Ziskin MC, Bagley JE, American Institute of Ultrasound in Medicine; Health Canada; British Medical Ultrasound Society. Comparison of Thermal Safety Practice Guidelines for Diagnostic Ultrasound Exposures. Ultrasound Med Biol. 2016;42:345-57.

55. Kilker BA, Holst JM, Hoffmann B. Bedside ocular ultrasound in the emergency department. Eur J Emerg Med 2014; 21:246-253.

56. Kendall CJ, Prager TC, Cheng H, Gombos D, Tang RA, Schiffman JS. Diagnostic Ophthalmic Ultrasound for Radiologists. Neuroimaging Clin N Am. 2015;25:327-65.

57. van Rhoon GC, Samaras T, Yarmolenko PS, Dewhirst MW, Neufeld E, Kuster N. CEM43 C thermal dose thresholds: a potential guide for magnetic resonance radiofrequency exposure levels? Eur Radiol 2013; 23(8):2215-27.

58. Abramowicz JS, Barnett SB, Duck FA, Edmonds PD, Hynynen KH, Ziskin MC. Fetal thermal effects of diagnostic ultrasound. J Ultrasound Med 2008; 27:541-559.

59. Herman BA, Harris GR. Theoretical study of steady-state temperature rise within the eye due to ultrasound insonation. IEEE Trans Ultrason Ferroelectr Freq Control. 1999;46:1566-74.

60. King RL, Liu Y, Harris GR. Quantification of temperature rise within the lens of the porcine 
eye caused by ultrasound insonation. Ultrasound Med Biol 2017; 43:476-481.

61. BMUS (British Medical Ultrasound Society). Guidelines for the safe use of diagnostic ultrasound equipment. Ultrasound 2010;18:52-59.

62. Silverman RH, Lizzi FL, Ursea BG, et al. Safety levels for exposure of cornea and lens to very high-frequency ultrasound. J Ultrasound Med 2001; 20:979-986.

63. Cucevic V, Brown AS, Foster FS. Thermal assessment of 40-MHz pulsed Doppler ultrasound in human eye. Ultrasound Med Biol 2005; 31: 565-573.

64. Lichtenstein DA, Menu Y. A bedside ultrasound sign ruling out pneumothorax in the critically ill. Lung sliding. Chest. 1995;108:1345-1348.

65. Sartori S, Tombesi P. Emerging roles for transthoracic ultrasonography in pleuropulmonary pathology. World J Radiol. 2010; 2:83-90.

66. Ahmad S, Eisen LA. Lung ultrasound: the basics. In Lumb P, Karakitsos D eds. Critical Care Ultrasound. Philadelphia: Elsevier, 2015 pp 105-137.

67. Copetti R, Cattarossi L, Macagno F, Violino M, Furlan R. Lung ultrasound in respiratory distress syndrome: a useful tool for early diagnosis. Neonatology. 2008;94:52-59.

68. Liu J, Liu F, Liu Y, Wang HW, Feng ZC. Lung ultrasonography for the diagnosis of severe neonatal pneumonia. Chest. 2014;146:383-388.

69. Pereda MA, Chavez MA, Hooper-Miele CC, et al. Lung ultrasound for the diagnosis of pneumonia in children: a meta-analysis. Pediatrics. 2015 ;135:714-722.

70. Volpicelli G, Elbarbary M, Blaivas M, et al. International evidence-based recommendations for point-of-care lung ultrasound. Intensive Care Med. 2012;38:577-91. 
71. Liu J, Copetti R, Sorantin E, Lovrenski J, Rodriguez-Fanjul J, Kurepa D, Feng X, Cattaross L, Zhang H, Hwang M, Yeh TF, Lipener Y, Lodha A, Wang JQ, Cao HY, Hu CB, Lyu GR, Qiu XR, Jia LQ, Wang XM, Ren XL, Guo JY, Gao YQ, Li JJ, Liu Y, Fu W, Wang Y, Lu ZL, Wang HW, Shang LL. Protocol and Guidelines for Point-of-Care Lung Ultrasound in Diagnosing Neonatal Pulmonary Diseases Based on International Expert Consensus. J Vis Exp. 2019 Mar 6;(145).

72. Chen SW, Fu W, Liu J, Wang Y. Routine application of lung ultrasonography in the neonatal intensive care unit. Medicine (Baltimore). 2017;96:e5826.

73. Oktem A, Yigit S, Oğuz B, Celik T, Haliloğlu M, Yurdakok M. Accuracy of lung ultrasonography in the diagnosis of respiratory distress syndrome in newborns. J Matern Fetal Neonatal Med. 2019 Apr 22:1-6.

74. Liu J, Chi JH, Ren XL, Li J, Chen YJ, Lu ZL, Liu Y, Fu W, Xia RM. Lung ultrasonography to diagnose pneumothorax of the newborn. Am J Emerg Med. 2017;35:1298-1302.

75. Martelius L, Heldt H, Lauerma K. B-Lines on Pediatric Lung Sonography: Comparison With Computed Tomography. J Ultrasound Med. 2016;35:153-7.

76. Child SZ, Hart man CL, Schery LA, Carstensen EL. Lung damage from exposure to pulsed ultrasound. Ultrasound Med Biol. 1990;16:817-25.

77. Miller DL. Induction of pulmonary hemorrhage in rats during diagnostic ultrasound. Ultrasound Med Biol. 2012;38:1476-1482.

78. Miller DL, Dou C, Raghavendran K. Pulmonary Capillary Hemorrhage Induced by FixedBeam Pulsed Ultrasound. Ultrasound Med Biol. 2015;41:2212-9. 
79. Miller DL, Dong Z, Dou C, Raghavendran K. Pulmonary Capillary Hemorrhage Induced by Different Imaging Modes of Diagnostic Ultrasound. Ultrasound Med Biol. 2018;44:10121021.

80. Miller DL, Dong Z, Dou C, Raghavendran K. Influence of Scan Duration on Pulmonary Capillary Hemorrhage Induced by Diagnostic Ultrasound. Ultrasound Med Biol. 2016;42:1942-50.

81. Miller DL, Dou C, Dong Z, Raghavendran K. The Influence of Dexmedetomidine on Ultrasound-induced Pulmonary Capillary Hemorrhage in Rats. Ultrasound Med Biol. 2016;42:964-70.

82. Miller DL, Dong Z, Dou C, Raghavendran K. Pulmonary Capillary Hemorrhage Induced by Diagnostic Ultrasound in Ventilated Rats. Ultrasound Med Biol. 2018;44:1810-1817.

83. O'Brien WD Jr, Simpson DG, Ho MH, Miller RJ, Frizzell LA, Zachary JF. Superthreshold behavior and threshold estimation of ultrasound-induced lung hemorrhage in pigs: role of age dependency. IEEE Trans Ultrason Ferroelectr Freq Control. 2003;50:153-69.

84. O'Brien WD Jr, Yang Y, Simpson DG, Frizzell LA, Miller RJ, Blue JP Jr, Zachary JF. Threshold estimation of ultrasound-induced lung hemorrhage in adult rabbits and comparison of thresholds in mice, rats, rabbits and pigs. Ultrasound Med Biol. 2006;32:1793-804.

85. Meltzer RS, Adsumelli R, Risher WH, Hicks GL Jr, Stern DH, Shah PM, Wojtczak JA, Lustik SJ, Gayeski TE, Shapiro JR, Carstensen EL. Lack of lung hemorrhage in humans after intraoperative transesophageal echocardiography with ultrasound exposure conditions 
similar to those causing lung hemorrhage in laboratory animals. J Am Soc Echocardiogr. 1998;11:57-60.

86. Miller DL. Mechanisms for Induction of Pulmonary Capillary Hemorrhage by Diagnostic Ultrasound: Review and Consideration of Acoustical Radiation Surface Pressure.

Ultrasound Med Biol. 2016;42:2743-2757.

87. Church CC, Carstensen EL, Nyborg WL, Carson PL, Frizzell LA, Bailey MR. The risk of exposure to diagnostic ultrasound in postnatal subjects: Nonthermal mechanisms. J Ultrasound Med 2008; 27:565-592.

88. Wax DB, Leibowitz AB. Radiologic assessment of potential sites for needle decompression of a tension pneumothorax. Anesth Analg. 2007;105:1385-8

89. Abramowicz JS. Benefits and risks of ultrasound in pregnancy. Semin Perinatol. 2013;37:295-300.

90. Ondeck CL, Pretorius D, McCaulley J, et al. Ultrasonographic prenatal imaging of fetal ocular and orbital abnormalities. Surv Ophthalmol. 2018;63:745-753.

91. Forward H, Yazar S, Hewitt AW, Khan J, Mountain JA, Pesudovs K, McKnight CM, Tan AX, Pennell CE, Mackey DA, Newnham JP. Multiple prenatal ultrasound scans and ocular development: 20-year follow-up of a randomized controlled trial. Ultrasound Obstet Gynecol. 2014;44:166-70.

92. Brenner DJ, Hall EJ. Computed tomography-an increasing source of radiation exposure. N Engl J Med 2007;357:2277-84.

93. Pearce MS, Salotti JA, Little MP, et al. Radiation exposure from CT scans in childhood and 
subsequent risk of leukemia and brain tumors: a retrospective cohort study. Lancet 2012;380:499-505.

94. Zacharias C, Alessio AM, Otto RK, et al. Pediatric CT: strategies to lower radiation dose. Am J Roentgenol 2013;200:950-56.

95. Goske MJ, Applegate KE, Bulas D, et al. Alliance for Radiation Safety in Pediatric Imaging. Image Gently: progress and challenges in CT education and advocacy. PediatrRadiol 2011;41:461-6.

96. Brody AS, Frush DP, Huda W, Brent RL. American Academy of Pediatrics Section on radiology: radiation risk to children from computed tomography. Pediatrics 2007;120:677_ 82.

97. Kucharzik T, Maaser C. Intestinal ultrasound and management of small bowel Crohn's disease. Therap Adv Gastroenterol. 2018;11:1756284818771367.

98. Sauer CG, Kugathasan S, Martin DR, Applegate KE. Medical radiation exposure in children with inflammatory bowel disease estimates high cumulative doses. Inflamm Bowel Dis. 2011;17:2326-32.

99. Beal EW, Sigmond BR, Sage-Silski L, Lahey S, Nguyen V, Bahner DP. Point-of-Care Ultrasound in General Surgery Residency Training: A Proposal for Milestones in Graduate Medical Education Ultrasound. J Ultrasound Med. 2017;36:2577-2584.

100. Deshpande R, Montealegre-Gallegos M, Matyal R, Belani K, Chawla N. Training the Anesthesiologist in Point-of-Care Ultrasound. Int Anesthesiol Clin. 2016;54:71-93.

101. Abo AM, Alade KH, Rempell RG, Kessler D, Fischer JW, Lewiss RE, Raio CC, Marin JR. 
Credentialing Pediatric Emergency Medicine Faculty in Point-of-Care Ultrasound: Expert Guidelines. Pediatr Emerg Care. 2019 Jan 7.

102. Stolz LA, Muruganandan KM, Bisanzo MC, et al. Point-of-care ultrasound education for non-physician clinicians in a resource-limited emergency department. Trop Med Int Health. 2015;20:1067-72.

103. SPOCUS. Guidelines for point of care ultrasound utilization in clinical practive. Society of Point of Care Ultrasound. Spocus.org/practice-guidelines. 2017.

104. Vinayak S, Sande J, Nisenbaum H, Nolsøe CP. Training Midwives to Perform Basic Obstetric Point-of-Care Ultrasound in Rural Areas Using a Tablet Platform and Mobile Phone Transmission Technology-A WFUMB COE Project. Ultrasound Med Biol. 2017;43:2125-2132.

105. Gharahbaghian L, Anderson KL, Lobo V, Huang RW, Poffenberger CM, Nguyen PD.Pointof-Care Ultrasound in Austere Environments: A Complete Review of Its Utilization, Pitfalls, and Technique for Common Applications in Austere Settings. Emerg Med Clin North Am. 2017;35:409-441.

This article is protected by copyright. All rights reserved. 
Table 1. A list of clinical conditions which can be potentially ascertained with ultrasonography at the bedside.

\section{Head:}

Skull fracture

Neonatal interventricular hemorrhage

Transcranial Doppler

\section{Ocular:}

Retinal detachment

Vitreous hemorrhage

Dilated optic nerve sheath (as manifestation of elevated intracranial pressure)

Globe rupture

Retrobulbar hemorrhage

\section{Face:}

Fluid in sinuses

Peritonsillar abscess

\section{Neck:}

Lymphadenopathy vs abscess

Thyroid masses

Orotracheal airway evaluation

\section{Cardiac:}

Cardiac activity in setting of cardiac arrest

Pericardial effusion

Cardiac tamponade

Estimation of left ventricular ejection fraction

Focal wall motion abnormality

Preload and response to therapy

Evaluation of right ventricular function

\section{Lung:}

Pleural effusion

Thoracentesis

Interstitial alveolar syndrome

Pulmonary edema

Pneumothorax

Acute heart failure 
Pneumonia

ARDS (Acute Respiratory Distress Syndrome)

\section{Abdomen:}

Biliary disease

Hemoperitoneum

Small Bowel Obstruction

Hernia

Appendicitis

Pyloric Stenosis

Intussusception

\section{Pelvic:}

Intrauterine pregnancy

Ectopic pregnancy

Ovarian masses

Ovarian torsion

Pelvic inflammatory disease

\section{Genitourinary:}

Hydronephrosis

Testicular torsion

Bladder volume (urinary retention)

\section{Procedural:}

Lumbar Puncture

Central Venous Catheterization

Peripheral vascular access

Regional anesthesia

Abscess localization

Paracentesis

Thoracentesis

Procedural complications

\section{Musculoskeletal:}

Fractures: Rib. Extremity, Skull

Tendon injuries

\section{Vascular:}

DVT

Superficial thrombophlebitis

This article is protected by copyright. All rights reserved. 
Abdominal Aortic Aneurysm

Aortic Dissection

Arterial thrombosis

IVC (volume assessment)

Arterial access 
Table 2. The values of recommended maximal output exposure levels for the two FDA 510k approval tracks, adapted from FDA [23]. For both Tracks, either the IspPA.3, or the MI limits may be used.

\begin{tabular}{lcccc}
\hline \hline USE & IsPTA.3 $\left(\mathrm{mW} \mathrm{cm}^{-2}\right)$ & TI & IspPA.3 $\left(\mathrm{W} \mathrm{cm}^{-2}\right)$ & MI \\
\hline & Pre-amendments Acoustic & Output Exposure Levels (Track 1) & \\
\hline Peripheral & 720 & - & 190 & 1.9 \\
Cardiac & 430 & - & 190 & 1.9 \\
Fetal \& Other* & 94 & - & 190 & 1.9 \\
Ophthalmic & 17 & - & 28 & 0.23 \\
\hline \multicolumn{5}{c}{ Output Display Standard Recommendations (Track 3) } \\
\hline Global & 720 & 190 & 1.9 \\
Maximum & 50 & 1.0 & - & 0.23 \\
Ophthalmic & & & \\
\hline \hline
\end{tabular}

* Abdominal, Intraoperative, Pediatric, Small Organ (breast, thyroid, testes, etc.), Neonatal Cephalic, Adult Cephalic

ISPTA.3 $_{\text {S }}$ Derated Spatial-Peak Temporal-Average Intensity

IsPPA. $3=$ Derated Spatial-Peak Pulse-Average Intensity

$\mathrm{TI}=$ Thermal Index

MI = Mechanical Index 
Table 3. Recommended limitations on exposure time for high TI settings of the appropriate TIS, TIB or TIC.

\begin{tabular}{|c|c|c|}
\hline \hline Thermal Index Range & Adult Scanning Time & Obstetric Scanning Time \\
\hline${ }^{\circ} \mathrm{C}$ & minutes & minutes \\
\hline$>6$ & Not Recommended & Not Recommended \\
\hline $5.0-6.0$ & $<0.25$ & Not Recommended \\
\hline $4.0-5.0$ & $<1$ & Not Recommended \\
\hline $3.0-4.0$ & $<4$ & Not Recommended \\
\hline $2.5-3.0$ & $<15$ & $<1$ \\
\hline $2.0-2.5$ & $<60$ & $<4$ \\
\hline $1.5-2.0$ & $<120$ & $<15$ \\
\hline $1.0-1.5$ & No Time Limit & $<30$ \\
\hline $0.7-1.0$ & No Time Limit & $<60$ \\
\hline$<0.7$ & No Time Limit & No Time Limit \\
\hline
\end{tabular}




\section{Figure Captions.}

Figure 1. A plot of the number of citations returned in a PubMed search for "point-of-care ultrasound” for each the last 15 years (* up to June 2019). The rapid development of a POCUS research literature testifies to its growing importance in medical practice.

Figure 2. Measured signals from a hydrophone in the scan plane of a $7.6 \mathrm{MHz}$ diagnostic ultrasound probe operated at an on-screen MI of 0.9 reduced (derated) to approximate the ultrasound values reaching a rat lung surface. The pulse wave form (a) is shown as pressure versus time, which is used to calculate the instantaneous and pulse average (horizontal line) intensities (b). In (b), the length of the line indicates the pulse duration of 320 ns. As the beam passes by the probe, a series of pulses was received (c), which related to the scan rate and the width of the beam. The pulse repetition frequency in (c) was $10 \mathrm{kHz}$ (100 $\mu$ s repetition period). The imaging was continuous at 39 frames-per- second, which is seen as a brief series of pulses, as in (c), repeated each $25.6 \mathrm{~ms}$ (d).

Figure 3. Recommended TI versus exposure time safety guidance for the appropriate TIS, TIB or TIC (Table 2). Note that on the logarithmic time scale, small changes in TI result in large changes in the recommended time limit. 


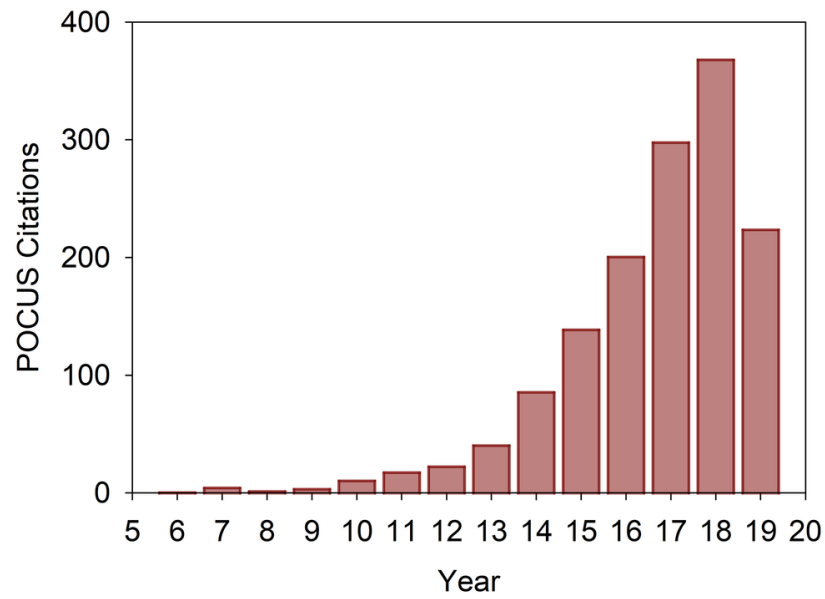

JUM_15202_Figure 1.tif 

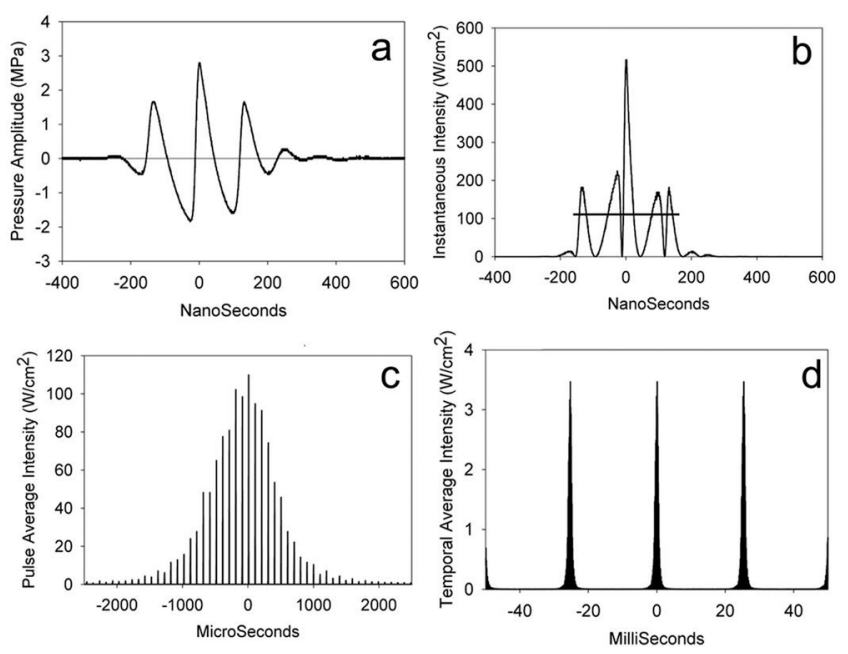

JUM_15202_Figure 2.tif

This article is protected by copyright. All rights reserved. 


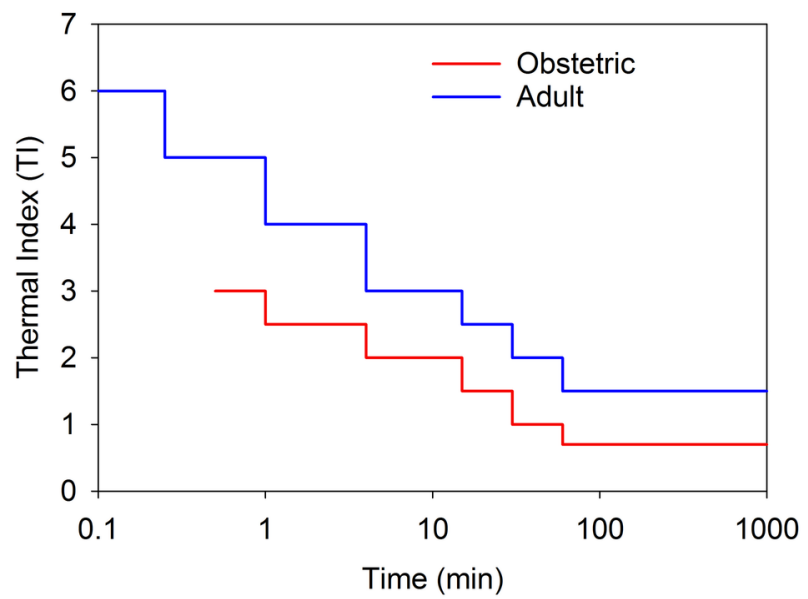

JUM_15202_Figure 3.tif

This article is protected by copyright. All rights reserved. 


\section{Please wait...}

If this message is not eventually replaced by the proper contents of the document, your PDF viewer may not be able to display this type of document.

You can upgrade to the latest version of Adobe Reader for Windows®, Mac, or Linux® by visiting http://www.adobe.com/go/reader_download.

For more assistance with Adobe Reader visit http://www.adobe.com/go/acrreader.

Windows is either a registered trademark or a trademark of Microsoft Corporation in the United States and/or other countries. Mac is a trademark
of Apple Inc., registered in the United States and other countries. Linux is the registered trademark of Linus Torvalds in the U.S. and other countries. 


\section{Please wait...}

If this message is not eventually replaced by the proper contents of the document, your PDF viewer may not be able to display this type of document.

You can upgrade to the latest version of Adobe Reader for Windows®, Mac, or Linux® by visiting http://www.adobe.com/go/reader_download.

For more assistance with Adobe Reader visit http://www.adobe.com/go/acrreader.

Windows is either a registered trademark or a trademark of Microsoft Corporation in the United States and/or other countries. Mac is a trademark
of Apple Inc., registered in the United States and other countries. Linux is the registered trademark of Linus Torvalds in the U.S. and other countries. 


\section{Please wait...}

If this message is not eventually replaced by the proper contents of the document, your PDF viewer may not be able to display this type of document.

You can upgrade to the latest version of Adobe Reader for Windows®, Mac, or Linux® by visiting http://www.adobe.com/go/reader_download.

For more assistance with Adobe Reader visit http://www.adobe.com/go/acrreader.

Windows is either a registered trademark or a trademark of Microsoft Corporation in the United States and/or other countries. Mac is a trademark
of Apple Inc., registered in the United States and other countries. Linux is the registered trademark of Linus Torvalds in the U.S. and other countries. 


\section{Please wait...}

If this message is not eventually replaced by the proper contents of the document, your PDF viewer may not be able to display this type of document.

You can upgrade to the latest version of Adobe Reader for Windows®, Mac, or Linux® by visiting http://www.adobe.com/go/reader_download.

For more assistance with Adobe Reader visit http://www.adobe.com/go/acrreader.

Windows is either a registered trademark or a trademark of Microsoft Corporation in the United States and/or other countries. Mac is a trademark
of Apple Inc., registered in the United States and other countries. Linux is the registered trademark of Linus Torvalds in the U.S. and other countries. 


\section{ICMJE Form for Disclosure of Potential Conflicts of Interest}

Instructions

The purpose of this form is to provide readers of your manuscript with information about your other interests that could influence how they receive and understand your work. The form is designed to be completed electronically and stored electronically. It contains programming that allows appropriate data display. Each author should submit a separate form and is responsible for the accuracy and completeness of the submitted information. The form is in six parts.

1. Identifying information.

2. The work under consideration for publication.

This section asks for information about the work that you have submitted for publication. The time frame for this reporting is that of the work itself, from the initial conception and planning to the present. The requested information is about resources that you received, either directly or indirectly (via your institution), to enable you to complete the work. Checking "No" means that you did the work without receiving any financial support from any third party -- that is, the work was supported by funds from the same institution that pays your salary and that institution did not receive third-party funds with which to pay you. If you or your institution received funds from a third party to support the work, such as a government granting agency, charitable foundation or commercial sponsor, check "Yes".

\section{Relevant financial activities outside the submitted work.}

This section asks about your financial relationships with entities in the bio-medical arena that could be perceived to influence, or that give the appearance of potentially influencing, what you wrote in the submitted work. You should disclose interactions with ANY entity that could be considered broadly relevant to the work. For example, if your article is about testing an epidermal growth factor receptor (EGFR) antagonist in lung cancer, you should report all associations with entities pursuing diagnostic or therapeutic strategies in cancer in general, not just in the area of EGFR or lung cancer.

Report all sources of revenue paid (or promised to be paid) directly to you or your institution on your behalf over the 36 months prior to submission of the work. This should include all monies from sources with relevance to the submitted work, not just monies from the entity that sponsored the research. Please note that your interactions with the work's sponsor that are outside the submitted work should also be listed here. If there is any question, it is usually better to disclose a relationship than not to do so.

For grants you have received for work outside the submitted work, you should disclose support ONLY from entities that could be perceived to be affected financially by the published work, such as drug companies, or foundations supported by entities that could be perceived to have a financial stake in the outcome. Public funding sources, such as government agencies, charitable foundations or academic institutions, need not be disclosed. For example, if a government agency sponsored a study in which you have been involved and drugs were provided by a pharmaceutical company, you need only list the pharmaceutical company.

\section{Intellectual Property.}

This section asks about patents and copyrights, whether pending, issued, licensed and/or receiving royalties.

\section{Relationships not covered above.}

Use this section to report other relationships or activities that readers could perceive to have influenced, or that give the appearance of potentially influencing, what you wrote in the submitted work.

\section{Definitions.}

Entity: government agency, foundation, commercial sponsor, academic institution, etc.

Grant: A grant from an entity, generally [but not always] paid to your organization

Personal Fees: Monies paid to you for services rendered, generally honoraria, royalties, or fees for consulting, lectures, speakers bureaus, expert testimony, employment, or other affiliations

Non-Financial Support: Examples include drugs/equipment supplied by the entity, travel paid by the entity, writing assistance, administrative support, etc.
Other: Anything not covered under the previous three boxes Pending: The patent has been filed but not issued Issued: The patent has been issued by the agency Licensed: The patent has been licensed to an entity, whether earning royalties or not

Royalties: Funds are coming in to you or your institution due to your patent 


\section{ICMJE Form for Disclosure of Potential Conflicts of Interest}

Section 1.

\section{Identifying Information}

1. Given Name (First Name)

Eitan

4. Are you the corresponding author?

5. Manuscript Title

Diagnostic Ultrasound Safety Review for POCUS Practitioners

6. Manuscript Identifying Number (if you know it)

JUM-2019-06-0599.R1

\section{Surname (Last Name)}

Dickman

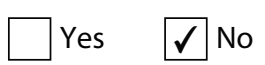

3. Date

30-September-2019

Corresponding Author's Name

Douglas Miller

\section{Section 2.}

\section{The Work Under Consideration for Publication}

Did you or your institution at any time receive payment or services from a third party (government, commercial, private foundation, etc.) for any aspect of the submitted work (including but not limited to grants, data monitoring board, study design, manuscript preparation, statistical analysis, etc.)?

Are there any relevant conflicts of interest? $\square$ Yes $\quad \checkmark$ No

\section{Section 3. Relevant financial activities outside the submitted work.}

Place a check in the appropriate boxes in the table to indicate whether you have financial relationships (regardless of amount of compensation) with entities as described in the instructions. Use one line for each entity; add as many lines as you need by clicking the "Add +" box. You should report relationships that were present during the $\mathbf{3 6}$ months prior to publication.

Are there any relevant conflicts of interest? $\square$ Yes $\square$ No

\section{Section 4. Intellectual Property -- Patents \& Copyrights}

Do you have any patents, whether planned, pending or issued, broadly relevant to the work? $\square$ Yes $\square$ No 


\section{ICMJE Form for Disclosure of Potential Conflicts of Interest}

\section{Section 5. Relationships not covered above}

Are there other relationships or activities that readers could perceive to have influenced, or that give the appearance of potentially influencing, what you wrote in the submitted work?

$\square$ Yes, the following relationships/conditions/circumstances are present (explain below):

$\checkmark$ No other relationships/conditions/circumstances that present a potential conflict of interest

At the time of manuscript acceptance, journals will ask authors to confirm and, if necessary, update their disclosure statements. On occasion, journals may ask authors to disclose further information about reported relationships.

\section{Section 6.}

\section{Disclosure Statement}

Based on the above disclosures, this form will automatically generate a disclosure statement, which will appear in the box below.

Dr. Dickman has nothing to disclose.

\section{Evaluation and Feedback}

Please visit http://www.icmje.org/cgi-bin/feedback to provide feedback on your experience with completing this form. 


\section{Please wait...}

If this message is not eventually replaced by the proper contents of the document, your PDF viewer may not be able to display this type of document.

You can upgrade to the latest version of Adobe Reader for Windows®, Mac, or Linux® by visiting http://www.adobe.com/go/reader_download.

For more assistance with Adobe Reader visit http://www.adobe.com/go/acrreader.

Windows is either a registered trademark or a trademark of Microsoft Corporation in the United States and/or other countries. Mac is a trademark
of Apple Inc., registered in the United States and other countries. Linux is the registered trademark of Linus Torvalds in the U.S. and other countries. 


\section{Please wait...}

If this message is not eventually replaced by the proper contents of the document, your PDF viewer may not be able to display this type of document.

You can upgrade to the latest version of Adobe Reader for Windows®, Mac, or Linux® by visiting http://www.adobe.com/go/reader_download.

For more assistance with Adobe Reader visit http://www.adobe.com/go/acrreader.

Windows is either a registered trademark or a trademark of Microsoft Corporation in the United States and/or other countries. Mac is a trademark
of Apple Inc., registered in the United States and other countries. Linux is the registered trademark of Linus Torvalds in the U.S. and other countries. 


\section{Please wait...}

If this message is not eventually replaced by the proper contents of the document, your PDF viewer may not be able to display this type of document.

You can upgrade to the latest version of Adobe Reader for Windows®, Mac, or Linux® by visiting http://www.adobe.com/go/reader_download.

For more assistance with Adobe Reader visit http://www.adobe.com/go/acrreader.

Windows is either a registered trademark or a trademark of Microsoft Corporation in the United States and/or other countries. Mac is a trademark
of Apple Inc., registered in the United States and other countries. Linux is the registered trademark of Linus Torvalds in the U.S. and other countries. 


\section{Please wait...}

If this message is not eventually replaced by the proper contents of the document, your PDF viewer may not be able to display this type of document.

You can upgrade to the latest version of Adobe Reader for Windows®, Mac, or Linux® by visiting http://www.adobe.com/go/reader_download.

For more assistance with Adobe Reader visit http://www.adobe.com/go/acrreader.

Windows is either a registered trademark or a trademark of Microsoft Corporation in the United States and/or other countries. Mac is a trademark
of Apple Inc., registered in the United States and other countries. Linux is the registered trademark of Linus Torvalds in the U.S. and other countries. 